\title{
Provision of Learning Support for University Students with Learning, Mental Health, and Other Forms of Hidden Disabilities
}

\author{
Emmanuel Manalo*, Jackie Ede and Glenis Wong-Toi
}

\author{
The Student Learning Centre, The University of Auckland, Private Bag 92019, Auckland 1142, New Zealand
}

\begin{abstract}
Much of the research on the topic of tertiary students with hidden disabilities has focused on attempting to understand the nature of these disabilities and their impact on students' academic performance. Very few studies have explored how effective learning support addresses the commonly reported problem of poor academic outcomes. Studies of the latter kind, however, are important in promoting not only learning at all levels - from the level of the students and their instructors, to those of institutional management and government policy makers - but also the development of effective institutional support mechanisms. This paper describes the support provisions of a university program that aims to facilitate better learning in students with hidden disabilities. Several indicators suggest that the program is achieving this aim. The increasing number of students using the program shows, among other things, that its support provisions are appropriate and are also viewed this way by students and referring agencies. An increasing proportion of students seeking not only assessment and accommodations, but also skills training, suggests that the program is succeeding in promoting student aspirations toward self-development and independent learning. Furthermore, student retention and pass rates indicate parity with other students, therefore addressing the issue of poorer academic performance of students with hidden disabilities. Three case studies illustrate the means by which Learning Advisors from the program assist students with hidden disabilities in meeting these students' learning development needs.
\end{abstract}

Keywords: University students with disabilities, hidden disabilities, student learning support, learning disabilities, attention deficit hyperactivity disorder (ADHD), mental health disabilities, student success and retention.

\section{INTRODUCTION}

Tertiary students (i.e., those at university, institutes of technology, community and vocational colleges, polytechnics, and other postsecondary education providers) who are affected by the experiences of "disabilities" are far greater in numbers than most people might initially expect. Those with physical, sensory, or mobility-related disabilities are often more 'visible' but, in most institutions, they constitute only a small minority. In contrast, students with "hidden" disabilities are usually indistinguishable from students without any form of disability and, in most tertiary environments, the proportions of students who fall into this category are quite significant.

Students with "hidden" disabilities are "a heterogeneous group encompassing major and minor psychiatric disabilities, attention deficit disorders, learning disabilities (LD), traumatic brain injury, and other neurocognitive disorders and chronic medical conditions that may compromise academic functioning" (p. 387) [1]. Most if not all of these conditions would be considered "mental health disorders" according to the Diagnostic and Statistical Manual of Mental Health Disorders, Fourth Edition (DSMIV) [2] as the manual includes not only categories of clinical syndromes but also developmental disorders like LD and specific learning disability (SLD), and attention deficit

*Address correspondence to this author at The Student Learning Centre, The University of Auckland, Private Bag 92019, Auckland 1142, New Zealand; Tel: +64-9-373-7599, Ext. 87896; Fax: +64-9-373-7076;

E-mail: e.manalo@auckland.ac.nz, emmanuel.manalo@gmail.com hyperactivity disorder (ADHD). However, this paper refers to "hidden disabilities" as it is more commonly used, both as a lay term and in the educational literature. Furthermore, ADHD is used to encapsulate all forms of attention deficit disorder in order to align with the literature presented in this paper.

Estimates of the prevalence of hidden disabilities vary, and this is, in part, due to a lack of general agreement regarding definitions and diagnoses of the disabilities [3-5]. The controversies surrounding definitions are outside the scope of this paper, but the following two examples clearly show that the numbers of students affected by hidden disabilities are far from negligible: one in every 11 first year students has been reported as having some form of LD, including ADHD [6], and a recent epidemiological study found that almost half of the students attending college had a psychiatric disorder in the preceding year, including alcohol use disorders and personality disorders [7].

Additionally, the numbers of students affected by hidden disabilities appear to be on the rise. This trend has, in part, been attributed to recent laws mandating access and services, as well as corresponding increases in government funding for special education programs and improvements in the overall understanding of the educational requirements of students with disabilities [1]. In addition, many tertiary institutions have acknowledged the need to address student equity issues and to abide by guidelines that may help towards achieving this $[8,9]$. This, no doubt, has also contributed to the increasing numbers of students with hidden disabilities in tertiary education. 
In the US, statistics indicate the increasing numbers of students with LD. In 1988, only $1 \%$ of college freshmen in 4-year institutions self-disclosed as having LD, whereas by 2000 the percentage was $2.4 \%$ [10]. In 2006, it was estimated that of the $11 \%$ of undergraduate students who self-identified as having some form of disability, $7.1 \%$ had LD [11]. These figures may underestimate the actual proportions of students with LD as many others may not disclose their disability for fear of negative repercussions $[11,12]$. In Australia, even more dramatic increases have been reported: between 1996 and 2003, for example, there has been an $88 \%$ increase in the numbers of students registering as having $\mathrm{LD}$, which compares to an increase of only $14.5 \%$ in the general university student population for the same period [13]. Apart from increases in the number of students identifying with LD, increases in demand for counseling services have been noted, especially for students with serious psychological problems [14-16].

Given that significant numbers of students at the tertiary level are affected by LD, mental health issues, and other hidden disabilities, it is crucial that adequate and comprehensive support is provided within the students' educational settings. While the provision of counseling, mental health support and disability services for tertiary students has been discussed extensively in the research literature, there is a comparative dearth of papers dealing with learning support services for students affected by hidden disabilities. Learning support services for these students may well be provided; however it appears that their outcomes have not been reported. Therefore, it is important to encourage researchers and practitioners to share knowledge and skills pertaining to the provision of learning support for students with hidden disabilities. By sharing the experiences of their work with these students, the authors of the present paper hope to contribute to the ongoing evaluation of such support, and to the subsequent and broader goal of developing more effective services for students with hidden disabilities.

This paper firstly addresses the learning challenges and needs of students with hidden disabilities - in particular, those with LD, ADHD, and mental health disorders. This is followed by a brief description of the categories of learning support that are available for these students at the tertiary level. The LD Program at the authors' university is introduced and described. An exploration of its effectiveness in terms of increasing student use, promotion of student aspirations toward self-development and independent learning, and retention and pass rates of students who have used the program is provided.

While student and faculty perceptions and experiences of the LD Program are highly relevant, this paper uses primarily quantitative data to assess the efficacy of the LD Program. This approach has been adopted in order to supplement current research on hidden disabilities, which tends towards qualitative reporting. In addition, this evidence-based methodology provides an external measure of success which contributes to the field's understanding of best-value interventions at tertiary level.

However, three brief case reports of students who have made use of the program have been included in order to illustrate the ways in which Learning Advisors who work in the program assist students in managing the learning difficulties they experience, teach them skills to effectively manage cognitive and metacognitive challenges relating to the demands of their courses, and support them when necessary in their interactions with instructors and administrators of the institution.

The LD Program presents an effective framework for meeting the diverse needs of tertiary students with hidden disabilities. It successfully engages these students in their learning process within an academic context. Furthermore, student retention and pass rates indicate parity with other students, therefore addressing the issue of poorer academic performance of students with hidden disabilities.

\section{THE LEARNING CHALLENGES AND NEEDS OF STUDENTS WITH HIDDEN DISABILITIES}

\section{Students with LD}

As previously noted, students with LD constitute a significant proportion of the student population with disabilities. LD often coexists with ADHD, as well as other mental health conditions such as mood, anxiety, and behavioral disorders [17]. However, the most common symptoms of students who have LD are reading, writing and/or spelling difficulties. Students diagnosed with "dyslexia" are subsumed under the LD category. Many individuals with LD have cognitive deficits in phonological processing which contribute to their academic difficulties because they can affect reading, spelling, note-taking, researching, and assignment writing [12].

Other areas in which students with LD commonly experience difficulties include various aspects of cognitive functioning (e.g., concentration, memory), spoken and written language (e.g., following and understanding lectures, comprehension of academic texts), executive functioning (e.g., planning and organization, meeting deadlines, managing time), and interpersonal skills (e.g., interacting with their peers and instructors, self advocacy) $[1,11,18]$. Many students with LD find it difficult to manage the academic rigor and more demanding thinking skills (e.g., critical and evaluative thinking) expected at the tertiary level. They have been found to procrastinate more, to possess lower levels of metacognitive self-regulation and selfefficacy for self-regulation [19], and to possess fewer test taking skills and higher levels of test anxiety compared to their peers without LD [20]. Even students with LD who are considered "gifted" can struggle in some aspects of their study management and performance, and have been found to possess lower academic self-efficacy [21].

Despite the increasing numbers of students with LD entering tertiary studies, their achievement outcomes, including graduation, are poor compared to their counterparts without LD, and their dropout rate remains high [22-25]. Apart from the direct manifestations of their specific difficulties (e.g., reading, writing, spelling problems) which may affect their academic performance, other more integrative and systemic explanations have been proposed. One is the extent to which students with LD achieve academic and social integration, and the significant influence that such integration has on their intent to persist with their studies [11]. Research suggests that all students 
need to effectively connect with other students and institutional staff, including their instructors, in meaningful ways [26-28]. This, however, may be difficult for students with LD not only because of possible deficits in interpersonal skills, but also the postsecondary institutional environments and their support systems may be poor in comparison to those at secondary level. In fact, reported barriers to the retention and success of students with LD include lack of understanding of students' conditions and requirements on the part of institutional staff and instructors, in addition to practices that make the students feel that they are not accepted as legitimate members of their learning communities $[13,29]$. Consequently, students may fail to disclose their LD and forego requests for accommodations for fear of discrimination and negative stigma.

\section{Students with ADHD}

ADHD is characterised by inappropriate levels of attention, and can occur with impulsivity and/or hyperactivity. Although ADHD is usually diagnosed in childhood, the disorder is considered as a lifelong problem for most who are affected as a significant proportion of children who are diagnosed with ADHD continue to experience symptoms in their adolescence and adulthood [30].

Students with ADHD have been reported as tending to achieve lower than average GPA (grade point average), to be more likely to be on academic probation, and to manifest more academic impairments and difficulties [30]. In other studies, students with ADHD have been described as experiencing problems with study skills, as well as specific academic skills that are usually expected at the tertiary level like note-taking, summarizing, outlining, and test taking [31]. Compared to students with and without LD, students with ADHD have also been found to be poorer in concentration, self-regulation and time management [32]. Additionally, they have been reported to have significantly higher levels of internal restlessness, and to experience more intrusive and task-unrelated thoughts [33-35]. These symptoms in particular could, at least in part, contribute to compromising their attention skills and academic performance [36]. However, their academic difficulties are likely to be due, not only to internal factors, but also to external factors including demanding study expectations at tertiary level, loss of family structure to support academic success (particularly for those who have to move away for college study), and absence of individualized educational services [30]. Congruent with this view, first year students with ADHD have been found to experience greater academic performance concerns and depressive symptoms during their transition to tertiary studies [37].

In a description of a nursing student with ADHD, the following study behaviors were noted: she produced sloppy and disorganized written work, required maximum amounts of time to complete administered assessments, interrupted others during class discussions, and tended to be insensitive and impulsive in dealing with others [38]. The authors suggested that the cognitive deficits manifested by adult students with ADHD are mainly in "executive functioning" rather than in language and comprehension. Hence, difficulties arise in self-control, goal directed behaviors, planning, problem solving, and adapting to challenging situations [38]. Apart from problems in executive functioning, other researchers have identified further cognitive deficits including working memory impairments (more specifically, in auditory-verbal working memory) [39]. Considering the close links between working memory abilities and academic achievement [40, 41], such deficits could well be one significant source of the impaired academic performance manifested by students with ADHD [39].

\section{Students with Mental Health Issues}

Mental health problems comprise another important category of hidden disabilities, and such problems can have serious, detrimental effects on students' academic performance. Numerous studies have investigated the effects of psychological distress on tertiary level students, and the findings indicate: higher levels of assessment anxiety, tendency to failure, lower GPA achievement, poorer selfand resource management, poorer resilience and persistence when faced with academic and other challenges, lower levels of academic self-efficacy, and poorer help-seeking behaviors [42-44]. These effects are congruent with a core element in the definition of psychopathology, which is that it has "adverse consequences" on the affected individual's wellbeing and ability to effectively function in everyday life [44].

Students with clinically diagnosed mental health conditions may find that the regular demands of academic studies trigger psychiatric symptoms. For example, students with a "soft" bipolar disorder have been found to experience increases in hypomanic episodes as a result of preparing for and sitting examinations [45]. Hypomanic symptoms include inflated self-esteem or grandiosity, decreased need for sleep, distractibility, and increased psychomotor agitation [45]. All these symptoms are likely to directly or indirectly lead to impairments in examination performance.

\section{Categories of Learning Support}

The kinds of academic help and support for students with hidden disabilities can be grouped under five categories:

1. Metacognitive/executive functioning advice and support. This includes addressing problems and developing skills relating to planning and organization, time and self-management, identification and use of available resources, and so on.

2. Cognitive functioning assessment and remedial support. This includes identifying and addressing issues relating to attention, working memory, reading, spelling, writing, and problem solving.

3. Course related instruction and support. This includes the provision of skills related to the specific requirements of the student's course of study. For example: understanding and addressing assignment requirements, developing subject-related writing skills, and preparing for specific modes of assessments.

4. Institutional environment support. This includes appropriate accommodations and other kinds of assistance to enable better management and equitable 
assessment within the institutional environment. For example: arrangement and provision of readers and/or note-takers, extra time and/or quiet space during examinations, and use of specialized software.

5. Personal guidance and support. This category includes support to manage emotional and other personal issues that directly impact on academic performance (e.g., stress, anxiety, depression, conflict, and decreased self-esteem, confidence or motivation).

One key concern when identifying and assisting students with hidden disabilities is their willingness to self-identify and seek help. For many, it is a major step to acknowledge their learning problems and fears associated with stigmatization and being perceived as "different" from their peers. For some groups, such as international students and other cultural groups (e.g., Asian Americans, Pacific Islanders), the rate of underutilization of available support services and resources is far more pronounced. This has been attributed to various factors including unfamiliarity with the nature of and processes involved in the services offered, attempting to resolve the problems on their own, and seeking help instead from family and/or friends [46, 47].

However, when students with hidden disabilities make use of support services and resources available through their institution, positive outcomes have been reported, including better retention rates $[48,49]$. It is therefore important that research in this area aims to enhance understanding not only of the learning difficulties of students with hidden disabilities, but also the features and mechanisms of learning support provisions that promote successful educational outcomes. It is the intention of the authors that the description of the support program provided in their university, along with the three case reports, will contribute towards such understanding.

\section{THE LEARNING DISABILITIES PROGRAM AT THE UNIVERSITY OF AUCKLAND}

The Learning Disabilities (LD) Program at the University of Auckland's Student Learning Centre (SLC) provides learning assessment and tailored ongoing academic instruction and support for the university's students with LD, ADHD, mental health issues, and other forms of impairment. The Program endorses the principles of Kia Ōrite, Achieving Equity: The New Zealand Code of Practice for an Inclusive Tertiary Education Environment for Students with Impairments [9]. While most of the instruction and support is provided through individual consultations with students, the program's specialist Learning Advisors also work in close collaboration with the university's Disability Services, Student Health and Counseling, and key personnel in the university's faculties and subject departments. Access to the LD Program is free and unrestricted; therefore students can self refer or, as occurs in the majority of cases, are referred from the other services/sections of the university.

The main objective of the LD Program is to teach the process skills necessary for academic success and, more specifically, how to manage a disability within the academic context. Thus, the work undertaken with students focuses on academic learning and performance, rather than the more administrative, pastoral and psychomedical aspects of managing a disability. These are handled by staff at Disability Services, and Student Health and Counseling.

The LD Program Learning Advisors provide assistance in all of the five categories of help/support noted earlier, but only in so far as they address students' learning needs. For example, if a student experiences stress or depression which could impact on his or her ability to manage course demands, then personal guidance and support may be provided in the form of explanatory memos to tutors explaining the student's condition, outlining accommodation requirements, and suggesting ways the tutors could assist the student. Detailed task analyses and skills training sessions based around workload management may also take place. However, the student would also be referred to an appropriate staff member in Health and Counseling to deal with the symptoms and root causes of the stress or depression.

Although the University of Auckland's LD Program shares many features with other support programs for students with disabilities at the tertiary level, it also incorporates a number of unique aspects which distinguishes it from these programs and contributes to its effectiveness. To elaborate, although the program works closely with Disability Services, it is not part of that service: rather it is an integral unit within the SLC, which has a strong profile within the university for promoting academic success in students. The Learning Advisors who contribute to the work of the LD Program are employed on academic/teaching contracts rather than general/administrative contracts, unlike staff in other university services. In varying degrees, these Learning Advisors contribute to other SLC programs, as well as to the development of teaching materials and, when time permits, to research. Additionally, they contribute to appropriate committees (e.g., teaching and learning, examinations, foundation studies) where they provide input on matters related to student learning and, more specifically, students with hidden and other forms of disabilities.

In order to provide effective delivery of services, the LD Program Learning Advisors possess a combination of appropriate academic qualifications, strong teaching backgrounds, and knowledge and experience in dealing with student learning impairments. In fact, the ability of the Learning Advisors to seamlessly provide to each student all of the five categories of learning support (noted earlier) is an important feature of the program, distinguishing it from others like it. For instance, instead of outsourcing psychometric and other assessments, the Learning Advisors are qualified to administer them to students on location at the SLC. Assessment reports can therefore be tailored to each student's requirements (e.g., accommodations, resources, instruction) within the context of the university environment. Furthermore, the Learning Advisors are knowledgeable on a wide range of teaching and learning approaches, and associated educational research; therefore they can bring these to bear when teaching and advising students with hidden disabilities. They also have the necessary credibility when advising faculty and departmental staff members about teaching and learning related matters as they pertain to the general or specific needs of students with disabilities. 


\section{SOME INDICATORS OF EFFECTIVENESS}

\section{Increasing Student Use}

Although assessment and support for students with learning impairments is one of the services that has been provided by the SLC since the Centre's establishment in 1985, the number of students making use of the LD Program remained relatively low until recent years. In 2002, for example, only 12 students sought assistance through the program, but in 2008 the total had increased to 155 students. By the end of the first semester of 2009 (first half of the year), 151 students had already made use of the program. These dramatic increases in usage can be attributed to a number of factors including: greater awareness about disabilities and support available within the university environment as well as in the wider community in New Zealand; acknowledgement of dyslexia by the New Zealand government which has led to improvements in screening and identification of disabilities within the secondary education system; closer working relationships established with other services, particularly Disability Services (which initiates a high proportion of referrals); and the acquisition of an additional half-time Learning Advisor whose work is almost entirely dedicated to providing the ongoing support that many students require. Furthermore, there appears to be a general shift in student perceptions about their disability as more appear willing to disclose their disability and take on assistance without feelings of stigma.

While inductions, learning assessments, and recommendations for special conditions accounted for half of the services provided to students (76) who used the LD Program in the first semester of 2009, the remaining 50\% (75 students) were provided not only with support related to special conditions but also various forms of skills development. Of the 75 students in the latter category, 68 received advice and/or training in self- and workload management skills, and 47 received instruction and support in writing skills development. Other main areas in which instruction and support were provided include: examination skills (44 students), self-advocacy skills (38 students), and use of assistive technology (28 students). This data shows that the majority of the 75 students received multiple forms of instruction, advice, and/or support.

More than half (53\%) of the students assisted through the LD Program in the first semester of 2009 identified with various forms of SLD, the biggest proportion of whom identified with dyslexia (43\%). Combined with those who had ADD or ADHD (7\%) and those with multiple disabilities (i.e., disorders occurring in comorbidity such as LD combined with mental health disorders or other hidden disabilities) (10\%), these students constituted almost $70 \%$ of the students who used the program. Other forms of disabilities included mental health disorders (15 students, or $10 \%$ of the total, including 4 with bipolar disorders), and handwriting disabilities ( 7 students). In total, only 6 students (4\% of the total) who accessed the services of the LD Program did so because of physical or sensory disabilities directly impacting on their learning performance. Thus, the overwhelming majority (96\%) of those who used the LD Program in the first semester of 2009 were students with "hidden" forms of disabilities.
Although statistics about student use of a service like the LD Program on its own cannot be taken as proof of the program's usefulness and/or effectiveness, there are indications in this case suggesting that the program is at least meeting its objectives. It is important, not only in the university setting but also in the wider community, that individuals with impairments acknowledge their learning difficulties and seek advice and/or assistance when appropriate. The increasing numbers of students using the LD Program is consistent with this aim: in other words, the numbers indicate an increasing willingness on the part of students to disclose their disabilities - even in cases where these are "hidden" - and to seek the necessary forms of assistance.

Another matter of particular importance in educational settings is the promotion of independent learning whereby students develop the desire to learn skills which will ultimately enable them to study without assistance from others. As noted earlier, half of the students now using the LD Program are not only seeking assessments and accommodations but also various forms of skills development. Thus, there are clear indications that the program is succeeding in promoting aspirations toward independent learning among the students with disabilities that it serves.

Finally, there is an increasing proportion of students returning at the beginning of each semester to use the services provided by the LD Program. In the first semester of 2008 , only 17 students ( $15 \%$ of the total students seen) had previously used the program. In the first semester of 2009 , the number had increased to 46 students $(30 \%$ of the total seen). This increasing number of students returning to use the LD Program suggests that they are finding its provisions helpful in meeting their learning requirements.

\section{Student Retention and Success}

At the time of writing this paper, 132 of the 151 students who made use of the LD Program in the first semester of 2009 had accessible academic records. The other 19 students either had inaccessible records or their examination results had not yet been entered in their records.

Table 1 shows the retention and attrition details of the students. While it is clearly difficult to draw conclusions based on this small sample, the retention rate of students with impairments accessing the LD Program, at 93\%, compares favorably with similar statistics within the University of Auckland. In the 2007/2008 period, for example, the university achieved an $87 \%$ retention rate for first year students.

The course success rates for students making use of the LD Program were also commendable (see Table 2). The results indicate that the students were enrolled in a total of 404 examinable courses, of which they passed 359. Consequently, their overall pass rate was $89 \%$, which again compares favorably with similar statistics within the University of Auckland: for example, the overall pass rate for undergraduate students is consistently around $80 \%$, and the overall pass rate for all students in 2008 was $86.5 \%$. Additionally, the students who used the LD Program received an A-grade or better in 82 of the $359(23 \%)$ courses they passed. 
It is of course not possible to claim that the high retention and pass rates of these students were due to uptake of the LD Program. There are many other factors that would have impacted on these students' academic performance, and it is possible that the more "able", more motivated, and more conscientious students took the initiative to make use of the support services available to them, including the LD Program. However, as the instruction and support provisions of the LD Program directly address learning barriers and academic needs of students with disabilities, it would be reasonable to assume that the Program in some ways helped in promoting academic success and progression among these students. To extrapolate, it is likely that many more of these students would have discontinued with their studies or failed more of their courses had they not received support from the program.

Table 1. Retention and Attrition Details of Students Seen in Semester 1, 2009

\begin{tabular}{|c|c|c|}
\hline \multicolumn{2}{|r|}{ Students Who ... } & \multirow{2}{*}{$\begin{array}{r}\text { Number } \\
151\end{array}$} \\
\hline a. & Were seen in the LD Program (total) & \\
\hline b. & Had accessible academic records & 132 \\
\hline c. & $\begin{array}{l}\text { Completed their courses of study } \\
\text { during the first semester }\end{array}$ & 3 \\
\hline d. & $\begin{array}{l}\text { Could have continued with their } \\
\text { studies in the second semester: }(\mathrm{b}-\mathrm{c})\end{array}$ & 129 \\
\hline e. & $\begin{array}{l}\text { Were suspended as a consequence of } \\
\text { unsatisfactory academic progress }\end{array}$ & 1 \\
\hline f. & Decided to discontinue temporarily & 3 \\
\hline g. & Decided to discontinue permanently & 5 \\
\hline h. & Continued with their studies in the second semester & 120 \\
\hline & Retention rate: $(h \div d) \times 100$ & $93 \%$ \\
\hline
\end{tabular}

Table 2. Examination Performance Details of Students Seen in Semester 1, 2009

\begin{tabular}{|l|l|c|c|}
\hline \multicolumn{2}{|c|}{ Students Who ... } & Number & Percentage \\
\hline \hline a. & Were seen in the LD Program (total) & 151 & $\dot{\text { V }}$ \\
\hline b. & Had accessible academic records & 132 & $\dot{\text { V }}$ \\
\hline c. & $\begin{array}{l}\text { Did not have exams } \\
\text { (graduate research students) }\end{array}$ & 3 & $\dot{\text { V }}$ \\
\hline d. & Sat exams & 129 & $\dot{\text { V }}$ \\
\hline e. & Passed half or more of their courses & 120 & $93 \%$ \\
\hline f. & Passed all of their courses & 102 & $79 \%$ \\
\hline
\end{tabular}

It is also worth noting that there are some variations in the academic performance of different groups of students who use the LD Program. For example, it appears that students with mental health disorders in general tend to take fewer courses. The 15 students with mental health disorders mentioned earlier took a total of only 38 examinable courses during Semester 1, an average of only 2.53 courses for each student (which compares to at least 3 or 4 courses per semester for most full-time undergraduate students). Their retention rate, at $83 \%$ was lower than the average of $93 \%$ for all students who used the LD Program in the first semester. Likewise, their overall pass rate, at $76 \%$, was lower than the overall pass rate of $89 \%$ for all students who accessed the LD Program. Whilst these results were generated from a small sample group, they do support the previously cited research findings of lower retention and success rates for students with mental health disorders [42-44]. These results are further qualified by the fact that the students with mental health issues who are referred to the LD Program tend to have more chronic and/or multiple disabilities and previous experience of academic failure. However, more importantly, these results indicate the need for further and ongoing development of LD Program so that it may more effectively promote retention and success outcomes for particular student groups, such as those with mental health disorders.

In the following subsection of this paper, three brief case reports of students who used the LD Program in Semester 1 are described in order to better illustrate the ways in which the program impacts on students' abilities to more effectively manage the demands of their courses of study. The three cases were included for several reasons. First, each case represented one of the three most prevalent disabilities (learning, attention deficit, mental health) that students present with, and there was sufficient gender representation (i.e., at least one male and one female). Second, these students sought assistance and advice on different kinds of learning issues - thus providing some insight into the diverse challenges presented by students when they come to use the program. Lastly, these student cases demonstrate how the Learning Advisors provide most, if not all, of the five categories of learning support (mentioned earlier) according to the specific needs of each student. Permission was obtained from each student for her/his case details to be included here, and pseudonyms have been used.

\section{Case Descriptions of Students Who Have Used the Program}

\section{Marcus, a Second Year Bachelor of Science Student (Majoring in Geophysics) with a Specific Learning Disability (SLD)}

Marcus was first diagnosed with an SLD, relating to slow processing speed, in 2005. While he has excellent perceptual reasoning and working memory, he is often slow to respond and, in timed situations, he can work accurately but not always quickly. Marcus received accommodations in high school (extra time in exams); therefore he contacted the LD Program early in 2008, at the outset of his first semester, with the intention of applying for extra time in university exams.

Marcus participated initially in two appointments which served as induction sessions. There was a deliberate break of several days between these sessions to ensure that Marcus had time to reflect on the information provided and formulate new questions. At his first session, Marcus took part in an in-depth interview during which an LD Program Learning Advisor outlined the criteria for special conditions, the types of assistance the program could offer, and the types of assistive technology that could be useful. Finally, Marcus undertook a learning preferences/styles assessment using a self-assessment tool developed by the Learning Advisors. 
The assessment results indicated that Marcus was a strong visual learner and should consider making use of visual study tools such as mind mapping.

At the first induction session Marcus identified an issue common to students with SLD, revealing that, whilst he needed extra time for tests and exams, he was also concerned that it would take him longer to research, prepare and write assignments than other students of similar cognitive ability [50]. Although Marcus had achieved good marks in high school, he felt that he lacked the study skills to achieve excellence at tertiary level. Furthermore, he was a competitive swimmer with a gruelling training schedule, which meant that he had to make the most of his available study time.

At the second induction session, Marcus' special conditions (an extra 20 minutes per hour in tests and exams) were confirmed. The process steps related to these accommodations were outlined and his academic goals were established. Marcus agreed to meet with the Learning Advisor on a bi-weekly basis for the duration of the semester and that they would focus on workload management, essay writing, and exam preparation skills. Given the principal goal of the LD Program is to encourage independent academic learning, Marcus was informed that no proofreading of his written work would be provided but that the Learning Advisor would work alongside him to teach the skills necessary for proficient editing.

It was important that Marcus learn how to manage his time effectively as slow processing speed and lack of automaticity in language often result in rushed or late assignments with no opportunity for effective proofreading. Marcus adopted a weekly diary and used color coding and highlighting to manage all aspects of his study. He learned that it was necessary to allocate additional time to preparation and reading for each lecture and to make sure that he set aside a weekly review timeslot when he could monitor his diary. Marcus was shown how to manage his diary retrospectively, working backwards from assignment due dates and making checkpoints well in advance. These techniques proved very effective as, over the course of 2008, Marcus met all laboratory and assignment submission dates.

Students with SLD perform better when working to their strengths [9]. The learning assessment indicated that Marcus preferred information in visual format, choosing diagrams and graphs over written text. This set the direction for future teaching practice as, whenever possible, teaching resources were given to Marcus in visual format. Marcus was shown how to progressively convert his course, reading, and summary notes into visual formats by way of concept, theory, and mind maps. During the bi-weekly sessions, Marcus learned how to use Inspiration, a visual mind mapping software program which made the most of his strong visual-spatial abilities [51]. He ultimately used these new strategies to good effect when preparing for exams, drawing large A3-size topic maps. This technique was particularly helpful in a science paper which required short essays, and contributed towards Marcus' final mark of an $\mathrm{A}^{+}$.

Collaborating with faculty can facilitate ease of entry into tertiary study for students with SLD [9]. Marcus was slow in formulating and responding to verbal questions and had difficulty producing written work within time constraints, impairments which could potentially impact on his ability to participate in tutorials and laboratories. To alleviate any problems, Marcus was given letters for all of his Course Coordinators, outlining his disability, the possible effects, and how staff might help. These letters produced an immediate result: Marcus was subsequently shifted into a less populated laboratory class with more individual tutor time so that he could complete tasks within the allocated time. On another occasion, a lecturer prioritized the course reading list for him.

Issues with self-esteem are a common thread weaving its way through the experiences of many of students with SLD. Marcus' previous learning assessments told the same story: they noted that he tended to limit himself with self-doubts. The one-to-one tutoring situation gave Marcus the opportunity to reflect on his study behavior, ask academic questions without feeling rushed and, if asked a searching question, he was given the time to answer reflectively. He could also ask for advice without fear that disclosure may, in some way, hinder him later. Over the course of 2008, Marcus grew in confidence and these positive learning experiences may have impacted on Marcus' grades. In the first semester he received an $\mathrm{A}^{+}, \mathrm{A}$, and $\mathrm{B}$. In the second semester, Marcus reduced to two courses due to swimming commitments, but he still achieved As for both courses.

\section{Leonie, a Third Year Bachelor of Arts Student (Majoring in Politics) with Attention Deficit Disorder (ADD)}

Leonie was diagnosed with ADD in early 2008 and referred to the LD Program by the Mental Health (MH) Coordinator of the University's Disability Services. Prior to that, she had received mixed academic grades and experienced ongoing frustration due to her inability to complete assignments on time and to her satisfaction. She felt that her grades did not reflect her knowledge and that she had reached a critical point in her studies when she could no longer write essays the night before and achieve pass marks. Leonie was receiving assistance from the $\mathrm{MH}$ Coordinator to address her anxiety and self esteem concerns. However, Leonie also did not fully understand the academic learning process; hence she was referred to the LD Program for advice and assistance.

Given that Leonie was newly diagnosed, it was deemed necessary to ensure, at the outset, that she understood how her impairment might potentially impact on her academic performance. For example, students with ADD often experience the absence of 'self talk', an inner voice reminding them to complete a task now instead of later [5254]. In Leonie's case, this led to overdue and/or hurried assignments. The Learning Advisor who worked with Leonie therefore proposed that she (the Learning Advisor) act as her (Leonie's) external goalkeeper, ensuring that she met her academic deadlines. They subsequently analysed Leonie's existing academic study habits to establish which patterns of behavior did or did not work for her. This gave Leonie the opportunity to identify aspects of her study behavior which needed to change.

The Learning Advisor had also observed that students with ADD often display strong learning style preferences. Leonie's learning style was assessed and she was found to be 
a strong visual learner, preferring diagrams and graphs over dense text. This highlighted a major issue for Leonie, as her chosen discipline was Politics which is, by necessity, textheavy. The Learning Advisor adjusted her teaching practice accordingly: for example, the Learning Advisor endeavoured to give Leonie all resources in a visual format.

Furthermore, like Marcus in the previous case report, Leonie was given a memo for her Course Coordinators which outlined her disability, its manifestations, and what tutors/lecturers could do to help. While disclosure was difficult, Leonie knew that an awareness of her disability might ease the process of asking for an extension when she really required it.

By the end of the initial sessions with the Learning Advisor, Leonie had established clear academic goals and an action plan detailing how to achieve them. She had committed to ongoing meetings with the possibility of extra academic coaching during the semester break. After each session, Leonie received a follow-up email outlining the goals for the upcoming weeks with an action plan, broken down into courses and/or assignments. Leonie used this email as an ongoing guide and as the starting point for the following session with the Learning Advisor, when they would ascertain whether she was on task and meeting her goals. The email was also forwarded to the MH Coordinator who met with Leonie on alternate weeks and further reinforced the goals.

Over the following months Leonie received tuition covering many academic skills areas. Research indicates that students with ADD benefit from the use of visual attention enhancers $[54,55]$. Therefore, Leonie was taught how to usefully highlight materials, write visual notes and plans, and use color-coding effectively. She was also introduced to Inspiration [51]. Her assignment writing progress was tracked by way of an essay writing process model, and a checklist approach was adopted to assist her through the exam revision process. By the end of the first semester 2008, Leonie had realised that studying in 20-minute bursts worked well for her, and that she needed to limit her focus to one assignment at a time, otherwise she tended to become overwhelmed and "lose control".

Workload management is frequently a major problem for students with ADD at tertiary level. Without efficient time management, students with ADD can easily reach an overload point where they are unable to focus on specific tasks. It was therefore imperative that Leonie micromanaged her study timetable from the outset of each semester. With the Learning Advisor, she identified any critical points during the upcoming semester (such as more than one assignment due in the same week) and managed her diary retrospectively from these dates, inserting early checkpoints to ensure she was on task.

Leonie worked diligently to improve her study and test taking habits for almost three semesters and, at the time of writing this paper, was starting to reap the benefits. She has consistently achieved her goal of submitting all assignments on time, despite a very heavy course load in the most recent semester. She achieved one of her best grades ever during summer school $\left(\mathrm{B}^{+}\right)$and she was delighted to learn that she had met the academic criteria for acceptance into the
Bachelor of Arts Honors degree, which is a valuable step towards progression into graduate studies. Helen, a Mature Student with a Bipolar Disorder,
Undertaking a Conjoint Degree in Science and Arts

Helen has attended university intermittently for over 8 years with a mixed level of success. She is diagnosed with rapid cycling bipolar disorder; thus, over the duration of a week, she can fluctuate from a highly motivated state and extreme enthusiasm for her studies to a depressive state with no energy or willingness to meet her course demands. This has led to several periods of hospitalization during her time at university and, by necessity, part-time study. Helen takes medication to moderate her mood swings; however, this has not always proved effective.

The MH Coordinator of Disability Services referred Helen to the SLC after she failed a mid-semester Chemistry test. It was clear that Helen needed to identify gaps in her learning and improve her test taking strategies. The Chemistry course in question was compulsory and one of two Helen needed to complete the Science component of her conjoint degree.

It is not uncommon for students with mental health disorders to request academic support when they are enrolled in the final courses of their degree. The reasons behind seeking assistance tend to be multi-faceted. Firstly, these are often compulsory courses which the student has deferred to the end of the degree because he or she expects them to be difficult. Secondly, the courses are often at a higher academic level and thus prove more demanding of the student, not only in the acquisition of knowledge, but also in terms of coursework management. Finally, the awareness that these courses are necessary for final completion seems to exacerbate anxiety levels in many students with mental health disorders. Furthermore, many of these students are accustomed to intermittent failure and start to question their own ability to complete their degree when the end is in sight.

Prior to her first meeting at the SLC, Helen gave permission to the $\mathrm{MH}$ Coordinator to disclose her disability to the LD Program's Learning Advisor. The $\mathrm{MH}$ Coordinator therefore outlined how Helen's bipolar disorder typically manifested and its effects on her academic performance. This informed the development of the teaching and learning support provided for Helen. However, direct information about Helen's disability was never formally elicited by the Learning Advisor because it fell outside the parameters of the "specialist learning advisor and student" relationship. Helen was, nonetheless, given the opportunity to discuss her disability if and when she thought it appropriate, such as during goal setting.

These clear but adequately flexible boundaries created a secure and more focused learning environment for Helen because, while she knew that the Learning Advisor was aware of her disability, she also knew that their task together was to improve her academic skills. Besides, Helen could freely discuss personal issues with other support people: more specifically, her external caseworkers and the Disability Services MH Coordinator who referred her to the LD Program. 
At their first meeting Helen and the Learning Advisor identified some long and short term goals related to successfully passing the final year Chemistry paper and her other final year English paper. Through interview and some assessments, they were able to establish that Helen was a visual/verbal learner and that, while she was aware of several effective study techniques, she was not at that time applying them to her own study.

When teaching bipolar students, it is important to identify the gaps in their learning [56]. To that effect, the Learning Advisor and Helen closely analyzed her failed mid-semester test paper, comparing her answers with the model answers. They methodically identified which topic areas contained new material, and which required further revision. It was apparent that, while Helen had made an attempt at revision, this course required extensive rote learning and gave her little opportunity to interpret data, which was usually one of her strengths. The issue was further confounded by the detrimental effect of medication on Helen's working memory. They therefore needed to identify effective rote learning strategies. Helen was consequently tutored in the use of highlighting, note taking, summary sheet writing and flashcards, and shown how to apply these in studying and revising for the Chemistry course.

Helen proved to be a punctual, responsive student. She tended to be very reflective about her study behavior and was often more critical about her performance than was warranted. She frequently began appointment sessions in an anxious state; however, after about ten minutes of open questioning, she would relax in the knowledge that she was on task and meeting her academic goals.

Helen succeeded in passing both her courses that semester, and was delighted to achieve a $\mathrm{C}^{+}$for the Chemistry course. She was unwell in the week before the exam so her achievement of a pass mark can, in part, be attributed to her determination and ability. However, without the additional skills she had developed in working with the Learning Advisor, achieving success in that course would have been much more difficult, given the demanding nature of the course, Helen's experience of failing the mid-semester test, and her illness during the week prior to the final examination.

Helen has now graduated with her first degree, beating the odds for completion for students with mental health disabilities [57]. She has undoubtedly benefitted from good pastoral care and collaboration between university service departments and faculty. On the part of the Learning Advisor who worked with her, an awareness of the triggers for Helen's episodes has also proved extremely helpful. On two occasions, the Learning Advisor accurately identified that Helen was experiencing a hyper manic episode and contacted the MH Coordinator at the point of early onset, thus speeding up the process for Helen's recovery.

\section{DISCUSSION AND CONCLUSION}

The provision of effective learning support for students with various forms of hidden disabilities is an important priority in tertiary education for a number of reasons. Students with hidden disabilities comprise a significant and increasing proportion of the student population. Thus, to ignore their learning needs would not only impact on institutional performance in student retention and completion, but it would also be tantamount to neglecting student equity obligations that most governments globally now require education providers to meet. While it continues to be vital that researchers seek a better understanding of the symptomatic manifestations of hidden disabilities and their impact on students' well-being and academic performance, it is equally important that researchers contribute to the development of more effective support mechanisms for these students. Of particular urgency is the development of learning support mechanisms that really do work and can produce tangible evidence to this effect. Such development has an element of urgency because the support mechanisms concerned are intended to address student learning needs and challenges which directly affect students' decisions to remain or discontinue, as well as whether they pass or fail; in other words their retention and completion outcomes. Retention and completion outcomes are increasingly becoming an essential measure of performance for most tertiary institutions worldwide as greater accountability is demanded in relation to funding and use of resources.

The LD Program described in this paper demonstrates tangible effectiveness on a number of different levels. Firstly, the significant increase in the number of students using the program suggests not only that the appropriate services are being provided, but also that the program has established effective cross-referral arrangements with other key service providers and academic departments in the institution, and that its strategies in alleviating common student concerns about self-identifying are meeting with some success. The increasing proportions of students who are adopting skills development options to address identified needs is also indicative of the program's effectiveness in promoting aspirations towards independent learning among the students it serves.

Retention and pass rate figures of students who have used the LD Program in the most recent semester suggest that these students are staying on and passing their courses at rates that are at least equivalent to the university's general student population. This finding indicates that the program is helping in redressing the usual problem of poorer retention and success rates for students with disabilities at the tertiary level. The three case studies provide illustrative examples of the mechanisms by which the program assists students in managing problems they are experiencing, teaches skills that enable them to deal with current and future manifestations of cognitive and metacognitive challenges, and supports them where necessary in their interactions and negotiations with their instructors and administrative staff/sections in their institution. Without these case studies, it could be difficult to imagine how such a program tangibly contributes to addressing retention and success issues in its day-to-day operation. Finally, the LD Program has received extremely positive feedback from students via biennial student perception surveys conducted by the University's Equity Office and unsolicited communications from students and university staff.

Notably, the majority of the research literature on students with hidden disabilities has focused on particular shortcomings in their cognitive and metacognitive skills: thus, programs aimed at addressing their learning 
performance need to appropriately and effectively identify and address such problems in each student it serves. In doing so, it is crucial that the current manifestations of the problem, as well as future capabilities in managing the problem, are considered. Hence, in teaching time management skills, for example, it would be necessary to deal not only with the current challenges the student may be facing in completing coursework and meeting deadlines, but also with how the student may be able to apply time management principles in future work. Likewise, it would be insufficient to teach reading and writing strategies to the student without ensuring that he or she is able to apply those to the requirements of his or her current courses of study.

There are, however, numerous other personal and environment-related issues that affect the academic performance of students with hidden disabilities, and support programs need to equally, but by no means solely, address these also. These issues include, for example, the students' academic and social integration $[11,46]$, poor help-seeking behaviors [42-44], and the potential for misunderstandings and negative interactions with their instructors and other university personnel $[13,29]$. Therefore, it is important that the problematic manifestations of such issues are addressed in a pragmatic manner. Instruction and/or assistance should again not only deal with current and pressing problems, but also set the stage for the student to be able to manage and, where possible, take greater responsibility in the future. For example, undertaking the necessary preparation for and practicing how to self-disclose and seek accommodations would be helpful in reducing the likelihood of a negative response both in the present and in the future.

The LD Program described in this paper is currently achieving less success with students who have mental health issues. As noted previously, there are many factors that are likely to contribute to this comparatively lower level of success, including the fact that many of the students with mental health issues who are referred to the LD Program often have chronic and/or multiple disabilities as well as prior experiences of academic failure and are therefore in critical need of help with their studies. Most of these students are facing serious challenges regarding their capabilities in self- and resource management, their resilience and persistence when faced with obstacles, and their notions of self-efficacy and confidence [42-44]. Nevertheless, the support provided for students with mental health issues is one of the many aspects of the program that requires ongoing consideration, evaluation, and strategies development for the future. This particular area of "weakness" highlights that it is essential for any learning support program for students to constantly identify and acknowledge areas that require improvements so that efforts can be made to address these. One further aspect of the program not mentioned thus far, but which requires attention, is the timeliness with which students are provided the assessment and/or support they require. The LD Program experiences busy periods, usually at the outset of each semester, so there is often a waiting period of at least one or two weeks before a new student can be seen. The Learning Advisors working in the program are investigating and trialling viable and appropriate strategies to rectify these current limitations.
Student profiles and learning development requirements are by no means static, and neither are the educational and social environments in which they operate, so it is vital that support programs are able to constantly adjust and innovate to be able to effectively meet their requirements. As noted at the beginning of this paper, sharing of knowledge and skills in the provision of learning support for students with hidden disabilities, or any other targeted groups of students for that matter, would help in achieving such aims for program development. The present authors, therefore, hope not only that the information provided in this paper is helpful to other researchers and practitioners, but that others are also encouraged to share their efforts, experiences, and findings in catering for the learning needs of students with hidden disabilities.

\section{REFERENCES}

[1] Wolf LE. College students with ADHD and other hidden disabilities. Ann N Y Acad Sci 2001; 931: 385-95.

[2] American Psychiatric Association. Diagnostic and statistical manual of mental disorders (4th ed.). Washington, DC: Author 1994.

[3] Hammill DD. A timely definition of learning disabilities. Fam Commun Health 1993; 16(3): 1-8.

[4] Shaw SF, Cullen JP, McGuire JM, Brinckerhoff LC. Operationalizing a definition of learning disabilities. J Learn Disabil 1995; 28: 586-97.

[5] Siegel LS. Issues in the definition and diagnosis of learning disabilities. J Learn Disabil 1999; 32: 304-19.

[6] Henderson C. College freshman with disabilities: A statistical profile. Washington DC: Heath Resource Center, 1999.

[7] Blanco C, Okuda M, Wright C, et al. Mental health of college students and their non-college-attending peers. Arch Gen Psychiatry 2008; 65(12): 1429-37.

[8] McLean P, Heagney M, Gardner K. Going global: the implications for students with a disability. Higher Educ Res Dev 2003; 22: 217 28.

[9] Tertiary Education Commission, New Zealand Ministry of Education. Kia Ōrite, achieving equity: The New Zealand code of practice for an inclusive tertiary education environment for students with impairments. Wellington, New Zealand: Author 2004.

[10] Henderson C. College freshmen with disabilities: a biennial statistical profile. Washington DC: Heath Resource Centre, 2001.

[11] DaDeppo LMW. Integration factors related to the academic success and intent to persist of college students with learning disabilities. Learn Disabil Res Pract 2009; 24: 122-31.

[12] Kirby JR, Silvestri R, Allingham BH, Parrila R, La Fave CB. Learning strategies and study approaches of postsecondary students with dyslexia. J Learn Disabil 2008; 41: 85-96.

[13] Ryan J. Learning disabilities in Australian universities: Hidden, ignored, and unwelcome. J Learn Disabil 2007; 40: 436-42.

[14] Gallagher R, Gill A, Sysko H. National survey of counseling center directors. Alexandria, VA: International Association of Counseling Services, 2000

[15] Gallagher R, Sysko H, Zhang B. National survey of counseling center directors. Alexandria, VA: International Association of Counseling Services 2001.

[16] Kitzrow MA. The mental health needs of today's college students: Challenges and recommendations. NASPA Stud Aff Admin High Educ J 2003; 41: 167-81.

[17] Marks D, Newcorn J, Halperin J. Psychiatric comorbidity of adult attention-deficit/hyperactivity disorder. Ann N Y Acad Sci 2001; 931: 216-38

[18] McLean P, Bruce G, Powell J. Learning disabilities in higher education. Melbourne, Australia: University of Melbourne and Monash University 1995.

[19] Klassen RM, Krawchuk LL, Lynch SL, Rajani S. Procrastination and motivation of undergraduates with learning disabilities: A mixed-methods inquiry. Learn Disabil Res Pract 2008; 23: 137-47.

[20] Holzer ML, Madaus JW, Bray MA, Kehle TJ. The test-taking strategy intervention for college students with learning disabilities. Learn Disabil Res Pract 2009; 24: 44-56. 
[21] Reis SM, Neu TW, McGuire JM. Case studies of high-ability students with learning disabilities who have achieved. Except Child 1997; 63: 463-79.

[22] Murray C, Goldstein DE, Nourse S, Edgar E. The postsecondary school attendance and completion rates of high school graduates with learning disabilities. Learn Disabil Res Pract 2000; 15: 11927.

[23] Rojewski JW. Occupational and educational aspirations and attainment of young adults with and without LD 2 years after high school completion. J Learn Disabil 1999; 32: 533-52.

[24] Vogel SA, Leonard F, Scales W, Hayeslip P, Hermansen J, Donnells $\mathrm{L}$. The national learning disabilities postsecondary data bank: An overview. J Learn Disabil 1998; 31: 234-47.

[25] Wagner M, Newman L, Cameto R, Garza N, Levine P. After high school: A first look at the postschool experiences of youth with disabilities. A Report from the National Longitudinal Transition Study-2 (NLTS2). Menlo Park, CA: SRI International 2005 [cited 2009 Sept 23]. Available from: www.nlts2.org/reports/2005V04/ nlts2 V̈reportV2005 $\mathbf{V} 04$ Vंcomplete.pdf

[26] Pascarella ET, Terenzini PT. Predicting freshman persistence and voluntary dropout decisions from a theoretical model. J Higher Educ 1980; 51: 60-75.

[27] Strauss LC, Volkwein JF. Predictors of student commitment at two-year and four-year institutions. J Higher Educ 2004; 75: 20327.

[28] Tinto V. Leaving college: Rethinking the causes and cures of student attrition. Chicago: University of Chicago Press 1993.

[29] Denhart H. Deconstructing barriers: Perceptions of students labeled with learning disabilities in higher education. J Learn Disabil 2008; 41: 483-97.

[30] Heiligenstein E, Guenther G, Levy A, Savino F, Fulwiler J. Psychological and academic functioning in college students with attention deficit hyperactivity disorder. J Am Coll Health 1999; 47(4): 181-5.

[31] Zwart LM, Kallemeyn LM. Peer-based coaching for college students with ADHD and learning disabilities. J Postsecondary Educ Disabil 2001; 15: 1-15.

[32] Reaser A, Prevatt A, Petscher Y, Proctor B. The learning and study strategies of college students with ADHD. Psychol Sch 2007; 44: 627-38.

[33] Weyandt LL, Iwaszuk W, Fulton K, et al. The Internal Restlessness Scale: Performance of college students with and without ADHD. J Learn Disabil 2003; 36: 382-9.

[34] Hines AM, Shaw GA. Intrusive thoughts, sensation seeking, and drug use in college students. Bull Psychon Soc 1993; 31: 541-4.

[35] Shaw G, Giambra L. Task unrelated thoughts of college students diagnosed as hyperactive in childhood. Dev Neuropsychol 1993; 9: 17-30.

[36] Weyandt LL, DuPaul G. ADHD in college students. J Atten Disord 2006; 10: 9-19.

[37] Rabiner DL, Anastopoulos AD, Costello J, Hoyle RH, Swartzwelder HS. Adjustment to college in students with ADHD. J Atten Disord 2008; 11: 689-99.

[38] Bradshaw MJ, Salzer JS. The nursing student with attention deficit hyperactivity disorder. Nurse Educ 2003; 28(4): 161-5.
[39] Gropper RJ, Tannock R. A pilot study of working memory and academic achievement in college students with ADHD. J Atten Disord 2009; 12: 574-81.

[40] Gathercole SE, Pickering SJ, Knight C, Stegmann Z. Working memory skills and educational attainment: Evidence from national curriculum assessments at 7 and 14 years of age. Appl Cogn Psychol 2004; 18: 1-16.

[41] Engle RW, Tuholski SW, Laughlin JE, Conway ARA. Working memory, short-term memory and general fluid intelligence: A latent variable approach. J Exp Psychol Gen 1999; 128: 309-31.

[42] Brackney B, Karabenick S. Psychopathology and academic performance: The role of motivation and learning strategies. J Couns Psychol 1995; 42: 456-65.

[43] Kessler R, Foster C, Saunders W, Stang P. Social consequences of psychiatric disorders, I: Educational attainment. Am J Psychiatry 1995; 152: 1026-32.

[44] Svanum S, Zody Z. Psychopathology and college grades. J Couns Psychol 2001; 48: 72-6.

[45] Nusslock R, Abramson LY, Harmon-Jones E, Allooy LB, Hogan ME. A goal-striving life event and the onset of hypomanic and depressive episodes and symptoms: Perspective from the behavioral approach system (BAS) dysregulation theory. J Abnorm Psychol 2007; 116: 105-15.

[46] Mori S. Addressing the mental health concerns of international students. J Couns Dev 2000; 78: 137-44.

[47] Narikiyo TA, Kameoka VA. Attributions of mental illness and judgments about help seeking among Japanese-American and White American students. J Couns Psychol 1992; 39: 363-9.

[48] Bishop J, Brenneman K. An initial assessment of a counseling center's role in retention. J Coll Stud Pers 1986; 27: 461-2.

[49] Wilson S, Mason T, Ewing M. Evaluating the impact of receiving university-based counseling services on student retention. J Couns Psychol 1997; 44: 316-20.

[50] Lee J. The challenge of dyslexia in adults. In: Townend J, Turner M, Eds. Dyslexia in practice: A guide for teachers. New York: Kluwer Academic/Plenum 2000; pp. 273-310.

[51] Inspiration Software Inc. [homepage on the Internet]; c2009 [cited 2009 Sept 24]. Available from: http://www.inspiration.com

[52] Barkley RA. Behavioral inhibition, sustained attention, and executive functions: Constructing a unifying theory of ADHD. Psychol Bull 1997; 12: 65-94.

[53] Fischer M, Barkley RA, Smallish L, Fletcher K. Executive functioning in hyperactive children as young adults: Attention, inhibition, response perseveration, and the impact of comorbidity. Dev Neuropsychol 2005; 27: 107-33.

[54] Weyandt L. An ADHD (Attention Deficit Hyperactivity Disorder) primer. Mawah, NJ: Lawrence Erlbaum Associates 2007.

[55] Belfiore PJ, Grskovic JA, Murphy AM, Zentall SS. The effects of antecedent color on reading for students with learning disabilities and co-occurring attention-deficit/hyperactivity disorder. J Learn Disabil 1996; 29: 432-8.

[56] Lynn GT. Survival strategies for parenting children with bipolar disorder. London: Jessica Kingsley 2000.

[57] Lee S, Tsang A, Breslau J, et al. Mental disorders and termination of education in high-income and low- and middle-income countries: Epidemiological study. Br J Psychiatry 2009; 194: 4117. 